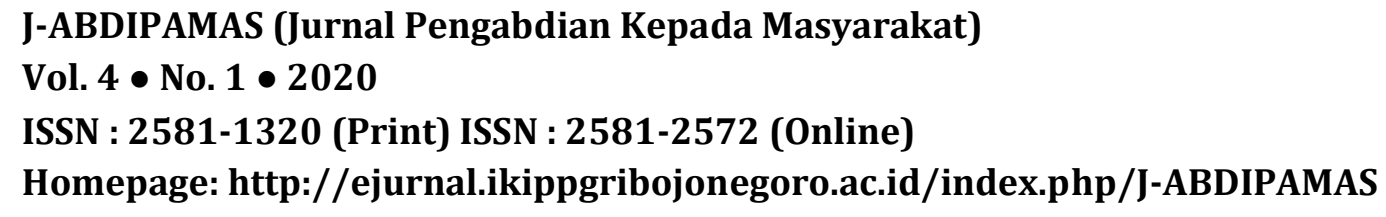

ISSN : 2581-1320 (Print) ISSN : 2581-2572 (Online)

Homepage: http://ejurnal.ikippgribojonegoro.ac.id/index.php/J-ABDIPAMAS

\title{
PEMBERDAYAAN MASYARAKAT DESA TABA REMANIK KECAMATAN SELANGIT KABUPATEN MUSI RAWAS MELALUI PELATIHAN PEMBUATAN KERUPUK KABAU
}

\author{
Harmoko $^{1}$, Dian Samitra ${ }^{2}$, Zico Fakhrur Rozi ${ }^{3}$ \\ ${ }^{1}$ STKIP PGRI Lubuklinggau. Email: putroharmoko@gmail.com \\ 2STKIP PGRI Lubuklinggau. Email: dian.samitra@gmail.com \\ 3STKIP PGRI Lubuklinggau. Email: zico.fakhrurrozi27@gmail.com
}

\begin{abstract}
This activity was motivated by income problem in community of Taba Remanik Village which is based on the agricultural sector where prices fluctuate. So that the family economy becomes weak. The partner regions are regions that have another commodity than rubber, namely: kabau. The kabau utilization in the partner regions has not been optimized. Therefore, partners especially PKK mothers, need to be equipped with the knowledge to utilize kabau so that it has high economic value. One of the method that can be used is to process the kabau into processed crackers. This service activity consists of 4 steps, namely: observation, delivery of material, practice of making crackers and monitoring evaluation. The material presented at the service activities are: Introduction of kabau, the nutritional content of kabau, the benefits of kabau and the practice of making kabau crackers. The community service activities in Taba Remanik Village went well and the community was very enthusiastic. The result of community service activities is that the community is able to practice how to make kabau crackers properly.
\end{abstract}

Keywords: Taba Remanik, Kabau, Crackers

\begin{abstract}
ABSTRAK
Kegiatan ini dilatarbelakangi oleh masalah penghasilan pada masyarakat Desa Taba Remanik yang bertumpu pada sektor pertanian dimana harga fluktuatif. Sehingga perekonomian keluarga menjadi lemah. Daerah mitra merupakan daerah yang memiliki komoditas sampingan selain karet, yaitu: kabau. Pemanfaatan buah kabau di daerah mitra belum optimal. Oleh karena itu, mitra terutama ibu-ibu PKK perlu dibekali pengetahuan untuk memanfaatkan buah kabau agar bernilai ekonomis tinggi. Salah satu cara yang dapat digunakan yaitu mengolah buah kabau menjadi olahan kerupuk. Kegiatan pengabdian ini terdiri dari 4 tahapan, yaitu: observasi, penyampaian materi, praktek pembuatan kerupuk dan monitoring evaluasi. Materi yang disampaikan pada kegiatan pengabdian tersebut yaitu: Pengenalan buah kabau, kandungan gizi buah kabau, manfaat buah kabau dan praktek pembuatan kerupuk buah kabau. Kegiatan pengabdian yang dilakukan di Desa Taba Remanik berjalan dengan baik dan masyarakat sangat antusias. Hasil kegiatan pengabdian kepada masyarakat ini adalah masyarakat mampu mempraktekkan cara membuat kerupuk buah kabau dengan baik.
\end{abstract}

Kata Kunci: Taba Remanik, Kabau, Kerupuk

\section{PENDAHULUAN}

Kecamatan Selangit adalah bagian dari Kabupaten Musi Rawas yang bagus, hal itu disebabkan Kecamatan Selangit berada di jalur lintas sumatera yang menghubungkan dari Provinsi Lampung sampai Aceh. Kecamatan Selangit sendiri memiliki 12 desa, dan salah satunya adalah Desa Taba Remanik. Desa Taba Remanik memiliki luas 12807,22 Ha, dengan luas tersebut menjadikan Desa Taba Remanik menjadi desa terluas kedua 
setelah Napal Melintang dengan luas 27238,48 Ha. Penghasilan masyarakat Desa Taba Remanik bertumpu pada sektor pertanian yaitu pada sektor perkebunan (karet), dengan luas lahan yaitu $310 \mathrm{Ha}$, selain karet juga ada Kopi yang menjadi penghasilan tambahan masyrakat Desa Taba Remanik. (BPS Kabupaten Musi Rawas, 2018).

Saat ini harga jual karet tidak menentu, rata-rata harga jual karet ditingkat petani sebesar Rp. 4.000-6.000/kg. Harga karet ditingkat petani yang tidak menentu menimbulkan ekonomi keluarga menjadi lemah. Hal ini menyebabkan masyarakat banyak beralih ke pekerjaan lain. Bahkan melemahnya tingkat ekonomi ini juga memberi dampak terhadap kriminalitas di lingkungan sekitar. Tentunya hal ini tidak bisa diabaikan, sehingga perlu solusi untuk meningkatkan taraf perekonomian keluarga.

Daerah mitra merupakan daerah yang memiliki komoditas sampingan selain karet, yaitu: kabau, petai dan kabau. Selain dimanfaatkan sebagai bahan lalapan, kabau telah dimanfaatkan sebagai bahan tambahan dalam pembuatan kerupuk kabau. Petai juga terdapat di daerah ini dan dimanfaatkan dengan baik, nilai ekonomi tinggi. Sedangkan kabau hanya dimanfaatkan sebagai bahan lalapan (makanan).

Buah Kabau atau dalam nama ilmiah dikenal dengan Archidendron bubalinum Jack I.C. Nielsen, adalah kerabat dekat Buah Jengkol dan dalam bahasa ilmiah dikenal sebagai Archidendron jiringa Jack I.C. Nielsen. Perbedaan mencolok dari keduanya yaitu dari ukuran dan bentuk buahnya, Kabau memiliki buah yang lebih kecil dibandingkan dengan Jengkol. Buah Kabau dapat ditemukan di Thailand, Semenanjung Malaya, dan Sumatera. Buah Kabau mempunyai nama daerah yang berbeda-beda, misalnya saja "kabau" (Jambi, Palembang, Riau), "jering utan" (Riau), "kabeu” (Bengkulu), "jering kabau" (Sumatra Barat), "julang-jaling" (Lampung), "kerdas" atau "jering tupai" (Malaysia), dan "nieng-nok" (Thailand) (Ghazali et al, 2014).

Buah Kabau sendiri oleh sebagian masyarakat dianggap tidak memiliki nilai ekonomi tinggi yang menyebabkan tumbuhan ini kurang populer di Indonesia jika dibandingkan dengan Jjengkol, sehingga belum dibudidayakan seperti halnya jengkol. Secara alami kabau tumbuh liar di hutan primer dan sekunder dataran rendah, namun banyaknya masyarakat yang mengubah hutan menjadi perkebunan karet dan sawit berdampak pada populasi kabau yang semakin berkurang (Komariah \& Hartana, 2016). Hal tersebut juga yang terjadi di Desa Taba Remanik, namun masyarakat tetap merawat dan memilihara pohon Kabau di tengah-tengah kebun Karet maupun Kopi. Karena memang, masyarakat memanfaatkan buah ini menjadi lalapan dan sambal yang menambah nafsu makan.

Berdasarkan kajian, memang buah kabau ini dapat menambah nafsu makan (Rahayu, et al, 2007), selain itu juga buah kabau ini juga bermanfaat sebagai: pestisida nabati (Utami \& Haneda, 2010); mengusir hama (Hilmanto, 2010); anti diabetes (Ong \& Azliza, 2015); dan antimelanogenesis (Arung et al, 2009). Begitu banyak sekali manfaat dari buah kabau ini, sehingga perlu dimanfaatkan secara maksimal. Mengingat jumlah pohon dan produksi kabau di daerah mitra sangatlah melimpah. Namun, tingkat konsumsi serta pemasaran yang rendah sehingga menyebabkan buah kabau banyak yang tidak termanfaatkan dengan baik. Hal inilah yang menjadi salah satu permasalahan yang dialami oleh mitra dan ingin diselesaikan oleh tim pengabdian. 
Beberapa permasalahan yang dialami oleh mitra, adalah sebagai berikut: 1) Harga komoditas karet yang rendah sehingga perekonomian mitra sedikit terganggu. 2) Kemampuan dan keterampilan mitra dalam memanfaatkan buah kabau menjadi kerupuk belum ada. Solusi yang dapat ditawarkan untuk mitra adalah sebagai berikut: 1) Meningkatkan perekonomian mitra dengan cara mengolah buah kabau supaya dapat menambah perekonomian mitra. 2) Mengadakan pelatihan tentang pembuatan kerupuk dari buah kabau, supaya masyarakat terampiil memanfaatkan komoditas yang ada di mitra.

\section{METODE PELAKSANAAN}

Tim dari STKIP PGRI Lubuklinggau akan melakukan kegiatan Program Pengabdian Masyarakat (PPM) dengan dibagi menjadi beberapa tahap, yaitu:

\section{Tahap Persiapan}

Pada tahap persiapan dilakukan survei lokasi dan koordinasi dengan para kelompok PKK dan kepala desa guna menentukan pelaksanaan kegiatan pembekalan dan pelatihan.

2. Tahap Pembekalan

Kegiatan pembekalan Kegiatan pembekalan pada kelompok PKK dengan materi yang disampaikan meliputi:

a. Potensi dan komoditi yang ada di sekitar untuk menambah pendapatan keluarga.

b. Tahapan pembuatan kerupuk dari olahan buah kabau.

c. Pembekalan pemasaran produk olahan buah kabau di desa Taba Remanik, Kecamatan Selangit, Kabupaten Musi Rawas.

\section{Tahap Pelatihan}

Pada tahap pelatihan yang dilakukan yang dilakukan tim Program Pengabdian Masyarakat (PPM). Tim PPM melakukan pelatihan tentang cara membuat kerupuk dari olahan buah kabau dan Tim PPM memberikan bantuan peralatan yang akan digunakan untuk untuk membuat kerupuk olahan buah kabau.

a. Bahan yang digunakan.

Bahan yang digunakan dalam pembuatan kerupuk kabau adalah sebagai berikut: Kabau, Tepung tapioka, air hangat, bawang putih, penyedap rasa secukupnya, garam dan minyak goreng.

b. Prosedur Pembuatan Kerupuk Kabau

1) Pertama-tama yang perlu dilakukan adalah buah kabau dikupas untuk diambil bagian bijinya, kemudian biji tersebut dicuci sampai bersih.

2) Kemudian kabau direndam dengan air bersih kira-kira selama 30 menit, dan air rendaman diganti dengan air bersih yang baru, lalu kabau direndam kembali selama 30 menit kembali, lakukan perendaman ini minimal sampai 3 kali. Jika sudah tiga kali angkat kabau dan tiriskan.

3) Setelah kegiatan perendaman selesai, buah kabau direbus dam panci dan ditambahkan garam secukupnya. Kabau direbus kurang lebih 30 menit sampai kuit ari pada biji kabau terkelupas. 
4) Setelah kulit ari banyak yang terkelupas, matikan kompor dan angkat biji kabau lalu ditiriskan, bersihkan kulit ari biji kabau sampai benar-benar bersih kemudian cuci sampai bersih lagi.

5) Biji Kabau yang sudah bersih, kemudian dihaluskan. Penghalusan biji kabau dapat dilakukan dengan menggunakan penumbuk (Alu dan Lumpang) ataupun bisa juga menggunakan blender.

6) Biji kabau yang sudah halus kemudian diletakkan pada wadah, dan ditambahkan bahan-bahan lainnya seperti tepung tapioka, bawang putih, garam, penyedap rasa, air hangat, aduk-aduk atau uleni sampai adonan rata sempurna.

7) Bentuk adonan tadi menjadi bulat memanjang, lalu bungkus dengan daun pisang atau plastik. Kemudian kukus hingga matang, kira-kira selama 40 menit. Setelah matang, angkat dan dinginkan.

8) Setelah dingin, lakukan pengirisan dengan pisau yang tajam dan usahakan jangan terlalu tebal karena kerupuk akan keras.

9) Kerupuk yang telah di iris kemudian dijemur dibawah sinar matahari sampai benar-benar kering.

10)Jika sudah benar-benar kering, kerupuk kabau sudah siap digoreng. Persiapkan penggorengan, dan goreng hingga matang. Kerupuk kabau sudah siap dihidangkan.

\section{Tahap Evaluasi}

Evaluasi program PPM ini dilakukan secara berkala setelah kegiatan berakhir, dilakukan setiap 1 bulan sekali. Evaluasi yang dilakukan meliputi:

a. Keberlanjutan dalam kegiatan PPM pembuatan kerupuk kabau.

b. Evalusi terhadap pemasaran dan promosi.

\section{HASIL DAN PEMBAHASAN}

Sebelum kegiatan pengabdian dilakukan, kami terlebih dahulu melakukan koordinasi dengan mitra yaitu desa Taba Remanik untuk merencanakan waktu dan tempat kegiatan pengabdian masyarakat di desa tersebut. Setelah waktu dan tempat disepakati, kami tim melakukan kegiatan pengabdian. Kegiatan tersebut dilakukan di balai Desa Taba Remanik.

Kegiatan selanjutnya yaitu pembekalan, pembekalan ini bertujuan untuk memberikan informasi dan pemahaman kepada peserta. Beberapa topik yang disampaikan antara lain: Potensi dan komoditi yang ada di sekitar untuk menambah pendapatan keluarga, Tahapan pembuatan kerupuk dari olahan buah kabau dan Pembekalan pemasaran produk olahan buah kabau di desa Taba Remanik, Kecamatan Selangit, Kabupaten Musi Rawas. Pada kegiatan ini, selain diberikan materi juga dilakukan diskusi Tanya jawab dan masyarakat sangat atusias untuk mengikuti kegiatan ini. Masyarakat sebelumnya hanya mengenal buah kabau sebagai lalapan atau sambal, namun ternyata bisa dimanfaatkan menjadi kerupuk. Selain itu juga masyarakat juga mengetahui bahwa kabau selain sebagai makanan juga dapat dijadikan sebagai obat. Beberapa daerah di Indonesia tumbuhan kabau telah digunakan sebagai obat tradisional 
seperti obat sakit perut dan penurun demam seperti di daerah Sumatera Utara. Biji kabau diketahui memiliki kandungan senyawa flavonoid, alkaloid dan saponin, sama dengan kandungan senyawa jengkol yang merupakan satu marga dengan kabau, selain itu ekstrak biji kabau (Archidendron buballinum (Jack.) I.C.Nielsen) berpengaruh terhadap penurunan kadar gula darah mencit putih jantan diabetes yang diinduksi aloksan (Komalasari, 2017; Triyandi et al, 2019).

Minggu berikutnya setelah dilakukan kegiatan pembekalan, dilanjutkan dengan kegiatan pelatihan. Pelatihan disini lebih cenderung ke arah praktek pembuatan kerupuk dari buah kabau. Pembuatan kerupuk kabau sama seperti pembuatan kerupukkerupuk yang lainnya, yang membedakan yaitu pada proses pengolahan kabaunya sebelum dicampur dengan bahan yang lain. Bahan yang digunakan dalam pembuatan kerupuk kabau adalah sebagai berikut: Kabau, Tepung tapioka, air hangat, bawang putih, penyedap rasa secukupnya, garam dan minyak goreng. Tahapan pembuatan kerupuk kabau dapat dilihat pada metode, dan hasilnya dapat dilihat pada Gambar 1 berikut ini.
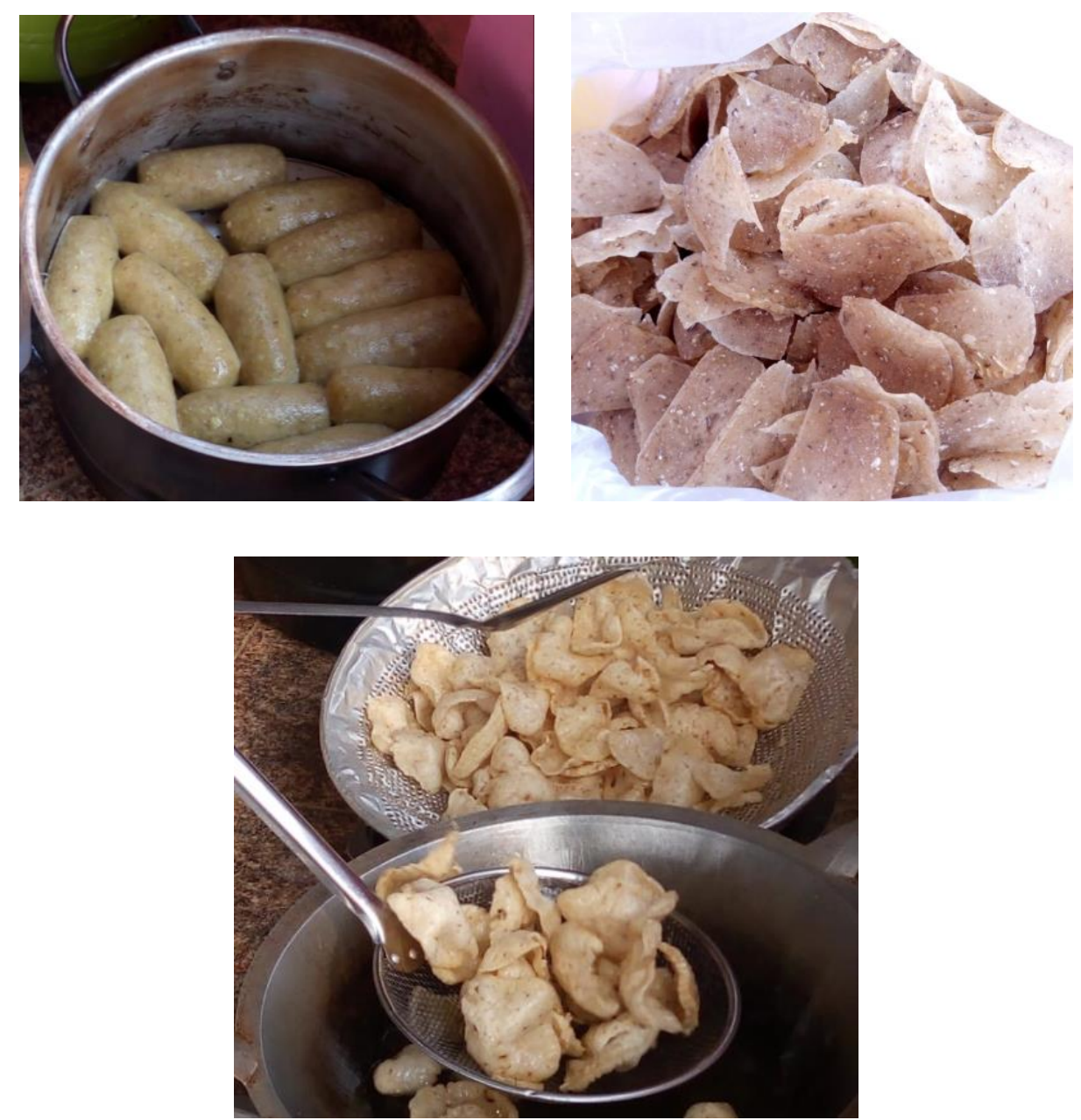

Gambar 1. Proses Tahapan Pembuatan Kerupuk Kabau

Kegiatan praktik pembuatan kerupuk kabau tidak menemui kendala, hal ini dikarenakan memang masyarakat sudah terbiasa melakukan pembuatan kerupuk, baik kerupuk ikan ataupun nasi. Yang membedakan hanya pengolahan buah kabaunya saja, 
sebelum dicampur dengan bahan-bahan lainnya. Secara umum, masyrakat sangat antusias untuk mengikuti praktek ini, tahap demi tahap diikuti dengan baik. Dan kemudian diakhir, kami menikmati kerupuk yang sudah jadi (dibuat sebelumnya dan siap goreng) dengan bersama-sama. Kepala desa Taba Remanik juga ikut dalam kegiatan tersebut, dan mendukung penuh kegiatan-kegiatan yang dilakukan oleh dosen STKIP PGRI Lubuklinggau dan berharap kerupuk kabau bisa menjadi oleh-oleh khas dari Desa Taba Remanik yang akan diproduksi dan dipasarkan melalui BUMDES.

Tahap terakhir setelah kegiatan praktek yaitu kami melakukan kegiatan evaluasi, secara umum masyarakat sudah memahami cara pembuatan kerupuk kabau dan sudah ada yang mempraktekkannya di rumah masing-masing. Sedangkan untuk kegiatan pemasaran dan promosi, masyarakat masih belum bisa melakukan, hal ini dikarenakan produksi kerupuk yang terbatas dan hanya dinikmati oleh keluarga saja.

\section{SIMPULAN}

Berdasarkan hasil pengabdian yang dilakukan, maka dapat disimpulkan bahwa: masyarakat sangat antusias dan senang dengan adanya kegiatan pengabdian ini, bauh kabau yang selama ini hanya untuk lalapan dapat dijadikan menjadi kerupuk yang memiliki nilai ekonomis tinggi.

\section{UCAPAN TERIMA KASIH}

Kami selaku tim pengabdian mengucapkan terimakasih atas pembiayaan pengabdian ini melalui hibah pengabdian STKIP PGRI Lubuklinggau. Kami juga mengucapkan terimakasih Kepada Bapak Kepala Desa Taba Remanik dan perangkatnya yang telah memfasilitasi kegiatan ini. sehingga kegiatan pengabdian ini dapat terlaksana dengan baik.

\section{DAFTAR RUJUKAN}

Arung, E. T., Kusuma, I. W., Christy, E. O., Shimizu, K., \& Kondo, R. (2009). Evaluation of Medicinal Plants from Central Kalimantan for Antimelanogenesis. J Nat Med, 63(2), 473-480.

BPS. (2018). Kecamatan Selangit dalam Angka. Musi Rawas: BPS Musi Rawas.

Ghazali., M. N., Masrom, H., Omar, Y., \& Aishah Farhana, S. (2014). A Preliminary Flora Survey In Gunung Kajang Pulau Tioman, Pahang Darul Makmur, Malaysia,. Malays. Appl. Biol, 43(2), 17-23.

Komalasari RA. (2017). Pengaruh Ekstrak Biji Kabau (Archidendron buballinum (Jack.) I.C.Nielsen) Terhadap Penurunan Kadar Gula Darah Mencit Putih Jantan Diabetes Yang Diinduksi Aloksan (Skripsi). Universitas Tulang Bawang Lampung.

Komariah, D., \& Hartana, A. (2016). Variasi Morfologi Kabau (Archidendron bubalinum) Dan Pemanfaatannya Di Sumatra. Floribunda, 5(5), 157-164.

Ong, H. C., \& Azliza, M. A. (2015). Medicinal Plants for Diabetes by the Orang Asli in Selangor, Malaysia. Ethno Med, 9(1), 77-84. 
Rahayu, M., Susiarti, S., \& Purwanto, Y. (2007). Kajian Pemanfaatan Tumbuhan Hutan Non Kayu oleh Masyarakat Lokal di Kawasan Konservasi PT . Wira Karya Sakti Sungai Tapa-Jambi. Biodiversitas, 8(1), 73-78.

Rudi, H. (2010). Etnoekologi. Lampung: Universitas Lampung.

Triyandi, R., Wahidah, L.K \& Firman. (2019). Pengaruh Fraksi Air Biji Kabau (Archidendron buballinum (Jack.) I.C.Nielsen) Terhadap Kadar Gula Darah Mencit Jantan Yang Diinduksi Aloksan. Jurnal Farmasi Lampung, 8(2), 123-131.

Utami, S., \& Haneda, F. N. (2010). Pemanfaatan Etnobotani dari Hutan Tropis Bengkulu sebagai Pestisida Nabati Utilization of Ethnobotany from Bengkulu Tropical Forest as Biopesticide Hasil dan Pembahasan. JMHT, 16(3), 143-147. 
18 J-Abdipamas, Vol. 4, No. 1 April, 2020 